\title{
EVALUATION OF HAEMATURIA AND USE OF PHASE CONTRAST MICROSCOPE: A SHORT REVIEW
}

\author{
SULTANA T ${ }^{1}$, SULTANA T ${ }^{2}$, RAHMAN MQ ${ }^{3}$, AHMED ANN ${ }^{4}$
}

\begin{abstract}
For centuries physicians have been using urine as one of the non-invasive means for assessing diseases. Haematuria is a frequently encountered abnormality in clinical practice. Haematuria may have either a glomerular or a non-glomerular origin. The morphological study of urinary red cells by Phase-Contrast Microscopy (PCM) is a useful diagnostic marker for glomerular bleeding, if correctly interpreted and used. Today, urinalysis and in particular identification of red cells morphology by Phase-Contrast Microscopy has been a widely accepted technique for determining the site of haematuria. A short review on haematuria and Phase-Contrast Microscopy are presented here for updating knowledge and academic interest.
\end{abstract}

Key words: Phase-contrast microscope, Haematuria, Dysmorphic red cell.

J Dhaka Med Coll. 2011; 20(1) : 63-67.

\section{Introduction:}

The patterns of renal diseases are different in different countries of the world, as it is influenced by geographical, environmental and socioeconomic factors in that region. Glomerular diseases are the leading cause of end stage renal disease (ESRD) throughout the world $^{1}$. The exact incidence of ESRD in the world is not known. The incidence of ESRD in developing countries is more than developed countries $^{2}$. In every year around 13000 new patients are likely to develop ESRD in Bangladesh $^{3}$. In our country, glomerulonephritis is the leading known cause accounting for $47 \%$ of ESRD 4 . Clinical presentation of glomerular diseases is ranging from asymptomatic presentation to impaired renal function of the patient ${ }^{5}$. Clinical diagnosis of specific glomerular diseases is difficult because the same glomerular disease can manifest in different ways. Due to the great variation of clinical manifestations of glomerular diseases, diagnosis depends on clinical features, the laboratory data and histopathological analysis.

Haematuria is the presence of blood in the urine, which is commonly divided into gross or macroscopic and microscopic haematuria ${ }^{6}$. Patient frequently present with haematuria in the out patient department of hospitals. Haematuria is a clinically significant finding associated with a number of conditions involving the genitourinary tract, including those of kidney, ureter, prostate, bladder and urethra ${ }^{7}$. Whatever the haematuria is transient or persistent, it should always be investigated in a proper way because of its important implications. Unfortunately little attention was paid to the renal parenchymal diseases the most common cause of microscopic haematuria, if untreated that could progress to renal failure. The causes of haematuria may be urinary lithiasis, glomerular and tubular diaseases, neoplasia or infection of the kidney and lower urinary tract and rupture of capillary blood vessels ${ }^{8}$.

1. Dr. Tahmina Sultana, Lecturer, Department of Pathology, Dhaka Medical College, Dhaka.

2. Dr.Tuhin Sultana, Associate Professor, Department of Clinical Pathology, Bangabandhu Sheikh Mujib Medical University (BSMMU), Dhaka.

3. Dr. Md. Quddusur Rahman, Associate Professor, Department of Clinical Pathology, Bangabandhu Sheikh Mujib Medical University (BSMMU), Dhaka.

4. Prof. A. N. Nashimuddin Ahmed, Professor and Chairman, Department of Clinical Pathology, Bangabandhu Sheikh Mujib Medical University (BSMMU), Dhaka.

For correspondence: Dr. Tahmina Sultana, Lecturer, Department of Pathology, Dhaka Medical College, Dhaka. Cell phone: +8801199158630, Email: tahmina94@yahoo.com 
Depending on the source of bleeding, haematuria can be classified as glomerular or dysmorphic red cells and non-glomerular or isomorphic red cells ${ }^{9}$. Both nephrologic and urologic invasive procedures are often performed in patient with haematuria in order to formulate a diagnosis. Glomerular diseases generally present with variable degrees of haematuria, proteinuria, and/or impaired renal function, singly or in combination ${ }^{10}$. Renal biopsy is the gold standard method for the diagnosis of GN, but it is an invasive, expensive, time consuming procedure and can be performed only in hospital admitted patients.

\section{Epidemiology:}

The prevalence of asymptomatic microscopic haematuria is ranging from $0.19-21 \%{ }^{11}$ due to wide variation in the definition of clinically significant microscopic haematuria. This range is largely accounted for by differences in age and sex in the populations studied. Persistent symptomless microscopic haematuria is a common condition ${ }^{12}$. The prevalence of isolated microscopic haematuria in children $\&$ adolescents is approximately $1.5 \%{ }^{13}$. Among school children the prevalence of haematuria is $0.5-2 \%{ }^{14}$. From population screening it was estimated that the prevalence of haematuria, both macroscopic and microscopic, may range from $5 \%$ to as high as $20 \%{ }^{15}$.

\section{Pathophysiology of haematuria:}

The pathophysiology of haematuria depends on the anatomic site within the urinary tract from which blood loss occurs. Blood originating from the nephron is termed as glomerular haematuria. In case of non-glomerular haematuria anything that disrupts the uroepithelium such as irritation, inflammation or invasion can result in normal appearing RBCs in the urine. Direct injury to the tubulointerstitium by infections, stones and ischemic necrosis of papillae can produce nonglomerular haematuria ${ }^{16}$. Malignant tumour, trauma, medications, cysts, infarction and arterio-venous malformations can also cause blood loss into the urinary space in nonglomerular haematuria ${ }^{17}$. The exact cause of dysmorphic red blood cells is not fully known.
It is thought to be the result of environmental changes that the cells are exposed through. The dysmorphic erythrocytes appear in the urine when the physiological barrier of the glomerulus for the passage of cells is disrupted. This barrier is composed of capillary endothelium, glomerular basement membrane and an epithelial layer - the podocytes ${ }^{18}$. When it has lost its barrier for erythrocytes, these cells follow the urinary flow along the tubular system ${ }^{19}$. It is thought to be the result of environmental changes that the cells are exposed through. During their course, the erythrocytes undergo alterations in shape. A combination of mechanical damage upon squeezing of red cells through the glomerular membrane followed by exposure to the changes of osmotic environment when cells pass through the tubular system ${ }^{20,21}$.

\section{Phase Contrast Microscope (PCM):}

Phase contrast is a method used in microscopy and developed in 1934 by Dutch physicist Frits Zernike. Phase is only useful on specimens that are colourless and transparent. These specimens are known as "phase objects". For this discovery Zernike was awarded the Nobel Prize (physics) in $1953^{22}$. Phase objects are transparent things that differ from their surrounding in optical path length. In Phase contrast microscope (PCM) by using optical filter, it transforms phase modulation into amplitude modulation, rendering the phase objects visible. Special condensers and objectives are used in phase contrast microscope. These alter the phase relationship of the light passing through the object and then passing around $\mathrm{it}^{23}$. The phase contrast microscope is now widely used for examination of biological tissues. Unstained living tissue specimens are transparent and provide little viewing contrast under brightfield microscopy. PCM is able to view unstained living tissues with enhanced viewing contrast, allowing the biological researcher to see details, which is normally unseen.

\section{Evaluation of haematuria and role of PCM}

The first step in the evaluation of haematuria is a thorough medical history, including medications and ingestion of foods etc. History, 
physical examination and simple laboratory tests are able to confirm many of common causes of haematuria ${ }^{14}$. The examination of urinary sediment is a diagnostic tool introduced into clinical practice more than 150 years ago and maintains its utility till today ${ }^{24}$. The urinary sediment examination is one of the most useful, and probably the single most cost-effective investigation in the assessment of health and diseases. Examination of the urine in patients with haematuria is essential, preferably before a patient is referred to a medical specialist. Microscopic examination of urinary sediment can increase the efficiency of the diagnostic process when it is performed at the start of the medical evaluation. One of the study shows $25 \%$ of patient could have spared from extensive urological investigation, if the examination of urinary sediment would have been performed at the start of evaluation ${ }^{25}$. At present a number of diagnostic tests many of them are invasive, are often performed in patient with haematuria. These test lead to increases expenditure, patient anxiety and discomfort.

The evaluation according to the manner of presentation can reduce the cost of the laboratory investigation ${ }^{26}$. After ensuring the presence of red blood cells in urine sediment by routine examination, next step is to determine the morphology of red cells by PCM. Birch and Fairley were the first to show that examination of the urinary sediment by phasecontrast microscope can help in the discrimination between glomerular and nonglomerular forms of haematuria ${ }^{27}$. This technique identifies glomerular erythrocytes by their variable shape with vacuole and usually with loss of membrane or destroyed forms of membrane. Haemoglobin content is reduced in glomerular erythrocyte, such erythrocyte appear to be doughnut-shaped as a result of decreased haemoglobin in the cytoplasm ${ }^{28}$. Non-glomerular erythrocytes are uniform in size, shape and have smooth outline ${ }^{29}$. Urinary sediment of patients with glomerular haematuria is characterised by the presence of a large variety of erythrocyte shapes. There is heterogeneity in shape and size of the erythrocytes, and also cell fragments can be found. Usually, at least three different shapes of erythrocytes are present in the urine of patients with glomerular disease, giving rise to a polymorphic picture, in contrast with nonglomerular haematuria in which all red cells are similar in shape (isomorphic), resulting in a monomorphic pattern ${ }^{30}$. Phase contrast microscopy is an accepted technique for evaluation of urinary red cell morphology due to more than $90 \%$ sensitivity and specificity. Most of the previous studies have reported sensitivity in the range of $89.8 \%$ to $100 \%$ and specificity of $90 \%$ to $100 \%$ for cut-off value of $20 \%$ for dysmorphic red cells by phase contrast microscopy $31,32,33,34$. The various forms of red blood cells in the urine were described by Bessis like discocytes, echinocyte, codocyte, acanthocyte etc ${ }^{35}$. G 1-cells are the special type of dysmorphic erythrocyte which has the form of a doughnut shape with target configuration, and membranous protrusions or blebs as a marker for glomerular haematuria ${ }^{36}$. Actually, erythrocytes with similar morphologic features to G1-cells had been previously observed in urine samples from patients with GN by Addis in 1948 and had been reported as acanthocytes by Kohler et al. (1991) (5) $^{35}$ Most of the studies have reported a cut off value of $5 \%$ for G1 cells ${ }^{31,37,38}$. The discovery of PCM has revolutionized the investigation protocol of the patients presented with haematuria. After nearly 30 years of this approach, a large number of techniques have been tried for detection of the dysmorphic red cells suggestive of glomerular haematuria. The techniques are phase-contrast microscopy $33,39,40$, bright-field microscopy with or without staining ${ }^{31,32,34}$, scanning electron microscopy ${ }^{41}$, automated urine analysis ${ }^{42,43}$. Apart from phase-contrast and bright-field microscopy, other techniques are time-consuming and some of them require costly equipment. Early detection of haematuria and differentiation between glomerular and non-glomerular type is very important for determination of the correct line of investigation and management.

\section{Conclusion:}

Laboratory medicine is in search of easier as well as economic techniques in the diagnosis of glomerular diseases. Examination of urinary 
red cell morphology using the phase contrast microscope is a relatively new and less explored technique in our country. Though the technique of PCM is simple, but it has still not become very popular in Bangladesh ${ }^{44}$. Possibly because lack of sufficient expertise in this field and specialized phase contrast microscope is needed for this technique. PCM is a simple, cost effective, non invasive technique which can be performed in out door patients. This method do not lead to a definite diagnosis, but enable the selection of the most appropriate test and thus avoid unnecessary, often invasive diagnostic procedure. In our country with limited resources, use of simple, cost effective, and reliable technique plays an important role in the diagnostic protocol of diseases. So the phase contrast microscopy may be incorporated as a part of standard urinalysis procedure to detect the site of haematuria.

\section{References:}

1. Bernieh B, Sirwal IA, Abbadi MA, Ashfaquddin M, Mohhammad O. The spectrum of glomerulonephritis in adults in Madinah Munawarah region. Saudi J Kidney Dis Transplant 2000; 11(3): 455-60.

2. Sakhuja V, Sud K. End stage renal disease in India and Pakistan: burden of disease and management issues. Kidney Int Suppl 2003; 83: S115-8.

3. Rashid HU. Health delivery system for renal disease care in Bangladesh. Saudi J Kidney Dis Transplant 2004; 15(2): 185-9.

4. Alam MR, Khanam A, Alam KS, Muqueet MA, Rahman H, Rashid HU. Prevalance of comorbidity in haemodialysis patient. Bangladesh Renal $\mathrm{J}$ 2004; 23(2): 56-60

5. Vinen CS, Oliveira. Acute glomerulonephritis. Postgraduate Med J 2003; 79: 206-13.

6. Mathew T. What to do when you find microhaematuria. Medical Observer 2004; 33.

7. Yates DR, Catto JF. Investigation of haematuria. The Foundation Years. 2006; 22: 80-2.

8. Mcdonald MM, Swagerty D, Wetzel L. Assessment of microscopic hematuria in adults. Am Fam Physician 2006; 73: 1748-54.

9. Birch DF, Fairley KF. Hematuria: a simple method for identifying glomerular bleeding. Kidney Int 1982; 21: 105-8

10. Walbaum D, Kluth D. Clinical assessment of renal disease. Medicine 2007; 35(7): 353-8.
11. Grossfeld GD, Litwin MS, Wolf JS, Hricak JRH, Shuler CL, Agerter DC, et al. Evaluation of asymptomatic microscopic hematuria in adults: the American Urological Association best practice policy. Part I: definition, detection, prevalence, and etiology. Urology. 2001; 57: 599-603.

12. Ballardie FW. Unexplained hematuria. BMJ 1990; 301(6762): 1171-2.

13. Fitzwater DS, Wyatt RJ. Hematuria. Pediatrics in Review 1994; 15(3): 101-8.

14. Cho BS, Kim SD. School urinalysis screening in Korea. Nephrology. 2007; 12: S3-7.

15. Edwards TJ, Andrew J, Gosling J, Mcgrath JS. A prospective analysis of the diagnostic yield resulting from the attendance of 4020 patients at a protocol-driven haematuria clinic. BJU Int 2006; 97: $301-5$

16. Macanovic M, Mathieson P. Primary glomerular disease. Medicine. 2007; 35: 490-6.

17. Vijayakumar M, Nammalwar BR. Diagnostic approach to a child with hematuria. Indian Pediatr 1998; 35: 525-32.

18. Junqueira LC, Carneiro J. Basic Histology. test and atlas. $11^{\text {th }}$ ed. New York: McGraw-Hill; 2006. p. 373-88.

19. Hussen J, Koene RAP, Hilbrands LB. The (fixed) urinary sediment, a simple and useful diagnostic tool in patients with haematuria. J Medicine 2004; 62(1): 1-9.

20. Rath B, Turner C, Hartley B, Chantler C. What makes red cells dysmorphic in glomerular haematuria? Pediatr Nephrol 1992;6:424-427.

21. Schramek P, Moritsch A, Haschkowitz H, Binder $\mathrm{BR}$, Maier $\mathrm{M}$. In vitro generation of dysmorphic erythrocytes. Kidney Int 1989; 36: 72-7.

22. Available from: http://www.olympusmicro.com/ primer/techniques/phasecontrast/ phaseindex. html [accessed on 10.12.2010].

23. Available from: http://en.wikipedia.org/wiki/ Phase_contrast_microscopy [accessed on 12.12.2010].

24. Fogazzi GB, Cameron JS. Urinary microscopy from the seventeenth century to the present day. Kidney Int 1996; 50: 1058-68.

25. Hussen J, Koene RAP, Hijbrands LB. Diagnostic a:roach in patients with asymptomatic haematuria: efficient or not? Int J Clin Pract 2006; 60: $557-61$.

26. Fogazzi GB, Geignani S. Urine microscopic analysis-an art abandoned by nephrologists. Nephrol Dial Transplant 1998; 13: 2485-7.

27. Birch DF, Fairley KF. Haematuria: glomerular or non-glomerular? Lancet 1979; 20: 845-6. 
28. Nagahama D, Yoshiko K, Watanabe M, Morita Y, Iwatani Y, Matsuo S. A useful new classification of dysmorphic urinary erythrocytes. Clin Exp Nephrol 2005; 9: 304-9.

29. Priscilla KS, Kenneth F. The Investigation of Hematuria. Semin Nephrol 2005; 25: 127-35.

30. Rabelink TJ. Unexplained haematuria. Nephrol Dial Transplant 1999; 14: 2025-7.

31. Dinda AK, Saxena S, Guleria S, Tiwari SC, Dash SC, Srivastava RN, et al. Diagnosis of glomerular haematuria:role of dysmorphic redcell, G1cells and brightfield microscopy. Scand J Clin Lab Invest 1997; 57: 203-8.

32. Abolfathi A, Hosaininasab A, Argani $H$. Differentiation of glomerular from non-glomerular hematuria by three different methods of microscopic examinations of erythrocytes in urine. IJMS 2007; 32(3): 163-8.

33. Mohammad KS, Bdesha AS, Snell ME, Witherow RON, Coleman DV. Phase contrast microscopic examination of urinary erythrocytes to localize source of bleeding: an overlooked technique? Clin Pathol 1993; 46: 642-5.

34. Mehta K, Tirthani D, Ali U. Urinary red cell morphology to detect site of hematuria. Indian Pediatr 1994; 31: 1039-45.

35. Kohler H, Wandel E, Brunck B. Acanthocyturiaa characteristic marker for glomerular bleeding. Kidney Int 1991; 40: 115-20.

36. Nguyen GK. Urine cytology in renal glomerular disease and value of G1 cell in the diagnosis of glomerular bleeding. Diagnostic Cytopathol 2003; 29(2): 67-73.
37. Lettgen B, Wohlmuth A. Validity of G1-cells in the differentiation between glomerular and nonglomerular haematuria in children. Pediatr Nephrol 1995; 9: 435-7.

38. Fogazzi GB, Edefonti A, Garigali G, Giani M, Zolin A, Raimondi $S$, et al. Urine erythrocyte morphology in patients with microscopic haematuria caused by a glomerulopathy. Pediatr Nephrol 2008; 23: 1093-100.

39. Fassett RG, Horgan BA, Mathew TH. Detection of glomerolar bleeding by phase-contrast microscopy. Lancet 1982; 26: 1432-4. ET

40. Rizzoni G, Braggion F, Zaechelio G. Evaluation of glomerular and non-glomerular hematuria by phasecontrast microscopy. J Pediatr 1983; 103: 370.

41. Pollock C, Pei-Ling L, Gyory AZ, Grigg R, Gallery $\mathrm{ED}$, Caterson R, et al. Dysmorphism of urinary red blood cells- value in diagnosis. Kidney Int 1989; 36: 1045-9.

42. Game X, Soulie M, Fontanilles A, Benoit J, Corberand JI, Pierre P. Comparison of red blood cell; volume distribution curves and phasecontrast microscopy in localization of the origin of hematuria. Urology 2003; 61: 507-11.

43. Kore RN, Dow CS, Deasi KM. A new automated system for urine analysis: a simple, cost-effective and reliable method for distinguishing between glomerular and non-glomerular sources of haematuria. BJU Int 1999; 84: 454-60.

44. Sultana T, Sultana T, Rahman MQ, Rahman F, Islam MS, Ahmed ANN. Value of dysmorphic red cells and G1 cells by phase contrast microscopy in the diagnosis of glomerular diseases. Mymensingh Med J 2011; 20(1): 71-7. 